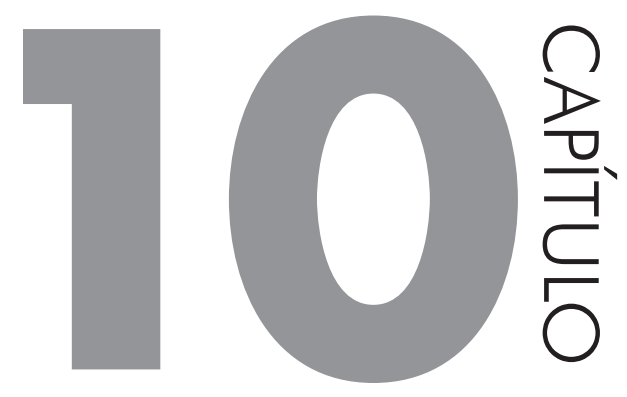

\title{
TUTORIA uma relação em rede com o ensino e a aprendizagem
}

\section{LUIZ CARLOS DOS P. SERPA ALFINO}

\section{UM CENÁRIO EM CURSO...}

Nos últimos anos, a partir do último quartel do século XX, os avanços tecnológicos têm contribuído bastante para um novo formato de ensino na sociedade contemporânea, marcando significativamente a sociedade Ocidental com uma nova linguagem comunicacional, possibilitando consideráveis mudanças na comunicação social, no sentido de tempo e espaço, intensificando a circulação de informações, conhecimentos e saberes.

À dinâmica das atividades educacionais cada vez mais tem ocupado espaço na sociedade informacional, ampliando os horizontes do ensino e da aprendizagem pela interação de ações e recursos disponibilizados em plataformas de ambientes virtuais de aprendizagem, além de diferentes canais e sistemas midiáticos participativos, como por exemplo, blogs, bibliotecas digitais, videoconferência, correio eletrônico, redes sociais, e outros aportes e plataformas com o uso da internet e de recursos tecnológicos disponíveis para tais fins, tornando-se parte integrante da vida cotidiana (WERTHEIN, 2000).

Nessa perspectiva encontra-se o trabalho da Tutoria, cujas ações transitam em espaços diversos de atuação, auxiliando as atividades docentes, me- 
diando conhecimentos e saberes, construindo pontes, criando e recriando redes de interação para o desenvolvimento do ensino e da aprendizagem nos espaços educacionais.

Atualmente os cursos constituídos na modalidade do Ensino a Distância (EaD), disponibilizam, em grande parte, suas atividades em plataformas de ambientes virtuais, cujo acompanhamento e orientação são dirimidos pelas intervenções docentes e de sua Tutoria. Nesse sentido, destaca-se a importância da Tutoria por, muitas vezes, ultrapassar as fronteias dos Ambientes Virtuais de Aprendizagem (AVA), dando também suporte, via e-mails, celulares, Whatsapp, redes sociais, entre outros, a partir de grupos formados em seus respectivos Polos de atuação, a fim de obter uma eficiência e eficácia ainda maiores no desenvolvimento de suas atividades profissionais e na aprendizagem discente.

A cultura digital tem contribuído para a inserção do sujeito num espaço, de sincronia, interação, pluralismo, mobilidade, ubiquidade e multiplicidades de objetos e percepções com mudanças de comportamento e uma heterogeneidade, cuja linguagem torna-se imprescindível para o desenvolvimento na interação de suas práticas, na intensificação de suas relações sociais, reconfigurando uma nova percepção e visão de um mundo multirreferenciado pelo cruzamento de vários produtos midiáticos, proporcionado pela cultura da sociedade informacional. Santos, Ponte, Stofella e Rossini (2015, p. 523) fazem, em breves linhas, uma análise sobre essas relações.

As relações sociais são intensificadas com presença das novas mídias que privilegiam a comunicação, a mobilidade e a ubiquidade. Conversas, narrativas e produções de artefatos culturais ocupam espaços-tempos e se constituem em interdiscursos que se realizam pelo cruzamento várias vozes presentes nas interfaces digitais. Compreender essa complexidade requer uma abordagem multirreferencial, um olhar holístico, uma leitura plural dos objetos (práticos ou teóricos), o que implica tanto visões específicas quanto linguagens apropriadas às descrições exigidas, em função de sistemas de referências distintos, considerados heterogêneos.

As atividades pedagógicas direta ou indiretamente desenvolvem interações em suas práticas. Muitas vezes essas interações advêm da própria dinâmica do mundo social vivido, cujos aspectos histórico e cultural trazem em seu bojo um lastro de ação instrumental. Nesse processo, a mediação e a internalização de saberes transitam numa intencionalidade para desenvolver ações que potencializam a aprendizagem. É nesse sentido que o trabalho docente e do Tutor pode ser visto mediando ações e recriando possibilidades para o desenvolvimento das potencialidades discentes com uma ação colaborativa. 


\section{UM CASO CONCRETO DE ZDP...}

Para citar um caso concreto, em uma atividade docente no curso de Licenciatura em Geografia/UFPE, modalidade EaD, na qual houve a imprescindível participação da Tutoria, percebeu-se, claramente, um caso de Zona de Desenvolvimento Proximal (ZDP), quando alguns alunos do curso tiveram grande dificuldade de entendimento na leitura de textos de autores clássicos da literatura de História, necessários às discussões temáticas propostas na disciplina.

Nesse momento investiu-se, como ação mediadora, na produção de vídeos-aula dos textos apresentados, retomando as discussões em fóruns como recurso interacionista para a internalização da aprendizagem, acompanhados também pela Tutoria de cada polo respectivo.

Com essas ações se pode perceber que todo o trabalho se desenvolveu por um conjunto de etapas que, a cada momento, trazia consigo o desafio de ampliar as possibilidades de aprendizagem, buscando no curso das atuações dialógicas desenvolvidas, a internalização do conhecimento numa construção/(re)construção dinâmicas; por uma racionalidade crítica e uma consciência intersubjetiva marcada por uma análise reflexiva de ação comunicativa (HABERMAS, 1989).

Por essa contextualização do lugar do sujeito no caso concreto, e de suas interações e possibilidades de acesso aos recursos tecnológicos que permeiam não só a cultura digital, mas também a cultura midiática se torna também inegável ter a compreensão de que os recursos tecnológicos aprimorados pela sociedade informacional tenham favorecido à ampliação de ações em ZDP's, contribuindo no trabalho de mediação pedagógica.

Esse trabalho não teria tido grande êxito caso não houvesse a mediação da Tutoria, repassando as orientações docentes e acompanhando a participação dos respectivos discentes, com o feedback de suas aprendizagens a partir dos vídeos-aula realizados no ambiente virtual da aprendizagem (AVA), para a internalização do conhecimento daquela temática, assim como no feedback das dificuldades encontradas em todo o percurso das ações.

Partindo desses pressupostos é possível ter a compreensão de que o trabalho da Tutoria é também, por assim dizer, um trabalho de construção de conhecimento e de compartilhamento de saberes e informações que medeiam em todo o percurso das atividades docentes, desde uma simples apresentação de seus conteúdos, ementas, planos de ensino e de curso, às últimas etapas de todo o planejamento; às avaliações e auto avaliações necessárias à criação de parâmetros para análise do desenvolvimento educacional e profissional.

Percebe-se, portanto, que muitas são as motivações de recursos tecnológicos que se encontram disponíveis para o desenvolvimento das práticas pedagógicas e, 
que, muitas vezes, também transcorrem 'naturalmente', em nosso uso cotidiano, trazendo certa ideia de "familiaridade", mas que, nem por isso, pode-se traduzir em autonomia.

Decerto que o uso cotidiano de alguns recursos tecnológicos facilitará as intervenções educacionais, dando-lhes pertinência quando necessária for sua utilização, mas é importante ter a compreensão de que, mesmo com o uso do mais avançado recurso tecnológico não se está isento a 'erros', pois, as limitações existem e também fazem parte do nosso dia a dia (MORIN, 2000).

Por essas razões também se compreende que as novas tecnologias da informação e comunicação têm exigido dentro da sociedade informacional a prerrogativa de "estarmos" conectados com o mundo, em uma "exigência" de inclusão digital quase que "coercitiva"; numa perspectiva que, muitas vezes, o simples fato de 'estarmos' conectados, traduz-se numa 'falsa ideia' de que também estamos em sintonia com o conhecimento.

\section{LIMITAÇÕES DO HOJE, DESAFIOS PARA O AMANHÃ...}

Infelizmente esse tem sido um deslocamento de razão e de coerência que se permeou na sociedade da informação, enquanto forma de apresentar determinadas percepções sobre o próprio sentido de adquirir conhecimento. Uma "falsa consciência" que induz a pensar e até a nivelar informação com conhecimento, como se tudo estivesse no mesmo plano de percepção e de desenvolvimento.

Esse tipo de 'percepção' reflete a fragilidade de entendimento crítico sobre a questão do conhecimento, carecendo de uma abordagem criteriosa de análise sobre instrumentos, informações e plataformas midiáticas que, muitas vezes, respaldadas pelo poder do capital, constroem suas relações discursivas com seus sujeitos legitimados e instituídos na ordem do discurso para o discurso da ordem capitalista (FOUCAULT, 2000).

Em contrapartida, entende-se também que não reconhecer o atual estágio de desenvolvimento tecnológico da sociedade informacional é, sem dúvida, optar a viver em um mundo cujas interações passam a existir em um novo sentido de espaço e tempo passados; de velocidades de informação e de suas interações que não mais coadunam com a realidade atual que vivemos.

Hoje, esse mundo regido pelo “ontem”, onde a velocidade de eventos excede, em muitos casos, nossa capacidade de interação, de modo que nos tornamos hipossuficientes para compreender, entender e vivenciar o movimento que movimenta a nossa própria realidade tem contribuído para nos tornarmos muito "instrumentais", técnicos e operacionais em detrimento do social-humano, pois o que se tem visto é a transferência da vivência real para a virtual e, dificilmente, o seu inverso... 
Se se a tecnologia trouxe consigo um espaço de interação multidimensional e multirreferencial, ressignificando o sentido de tempo e espaço, assim como de princípios e valores culturais com a velocidade do agora, não se pode deixar de registrar que a mesma velocidade do ontem não estará isenta de deixar limitações no hoje e também no amanhã, pela própria ideia norteadora de valores e princípios não possuírem a mesma velocidade da mudança.

Esses são alguns dos desafios em perspectiva que nos aguardam no devir, mas que já fazem parte de nossas reflexões e apreensões no tempo presente. Isso porque a própria tecnologia tem nos colocado no curso da 'transição', do 'fazendo', do 'passando', do 'realizando' e nunca do feito, do passado e do realizado e acabado.

Essas questões também nos levam a refletir que o tempo que vivemos é o da transição, é o tempo da mudança... É do pequeno lapso temporal que dará, ou pelo menos, tentará dar conta do macrossocial das relações sociais e de suas interações em rede. Mas o porvir deverá nos reservar uma nova tecnologia que, provavelmente, ampliará outras dimensões.

Você imagina como será a educação no futuro? E o trabalho da Tutoria, já pensou nisso?

\section{REFERÊNCIAS}

FOUCAULT, M. A ordem do discurso. 6 ed. São Paulo: Edições Loyola, 2000.

HABERMAS, J. Consciência moral e agir comunicativo. Rio de Janeiro: Tempo Brasileiro, 1989.

MORIN, E. Os sete saberes necessários à educação do futuro. 2 ed. São Paulo: Cortez; Brasília-DF: UNESCO, 2000.

SANTOS, E; PONTE, F. S; STOFELLA, T; ROSSINI, S. Autoria em rede: uma prática pedagógica emergente. Revista Diálogo Educacional, v.15, n. 45, p. 515-536, 2015. DOI: 10.7213/dialogo.educ.15.045.DS07

WERTHEIN, J. A sociedade da informação e seus desafios. Ciência da Informação, v. 29, n. 2, p. 71-77, 2000. DOI: 10.1590/S0100-19652000000200009 
